\title{
Nasal continuous positive airway pressure influences bottle-feeding in preterm lambs
}

\author{
Nathalie Samson ${ }^{1}$, Audrey Michaud ${ }^{1}$, Rahmeh Othman ${ }^{1}$, Charlène Nadeau ${ }^{1}$, Stéphanie Nault ${ }^{1}$, Danny Cantin ${ }^{1}$, \\ Michaël Sage ${ }^{1}$, Céline Catelin ${ }^{1}$ and Jean-Paul Praud ${ }^{1}$
}

BACKGROUND: In preterm infants, the time from initiation to full oral feeding can take weeks, which represents a very worrisome problem in neonatal medicine. Although current knowledge suggests that oral feeding should be introduced early, this is often delayed due to the need for prolonged nasal continuous positive airway pressure (nCPAP). Indeed, most caregivers fear that nCPAP could disrupt suckingswallowing-breathing coordination and induce tracheal aspiration. The goal of the present study was to assess the impact of nCPAP delivered by the Infant Flow System on the physiology of sucking-swallowing-breathing coordination during bottle-feeding in preterm lambs over $24 \mathrm{~h}$.

METHODS: Seventeen lambs (8 control, 9 nCPAP of $6 \mathrm{cmH}_{2} \mathrm{O}$ ) born 14 days prematurely were instrumented to record sucking, swallowing, respiration, ECG, and oxygenation. They were fed via a nasogastric tube for the first 5 days of life until introduction of bottle-feeding every $4 \mathrm{~h}$ for $24 \mathrm{~h}$.

RESULTS: nCPAP increased the feeding efficiency while maintaining higher oxygenation without any deleterious cardiorespiratory events. However, coughs were observed in lambs under nCPAP immediately following bottle-feeding and may be related to the high milk flow in preterm lambs.

CONCLUSION: Further studies documenting tracheal aspirations are needed, especially in preterm lambs under nCPAP for moderate respiratory difficulties, to further inform future clinical studies.

O ral feeding in infants is a complex motor activity that requires efficient coordination between sucking, swallowing, and breathing. Feeding difficulties represent one of the most worrisome problems encountered in preterm infants. Indeed, while neurological and digestive immaturity as well as persisting respiratory difficulties lead to delays in oral feeding introduction, current knowledge strongly suggests that early introduction accelerates feeding maturation in preterm infants $(1,2)$. A major hurdle for feeding introduction in preterm infants consists in the frequent requirement of nasal respiratory support in the form of high flow nasal cannula or nasal continuous positive airway pressure
(nCPAP) for several weeks after birth. Although both are widely used, the relative use of one or the other is mainly a matter of local preference. Introduction of oral feeding under nasal respiratory support, especially nCPAP, is highly controversial and a much-debated topic among neonatologists, due to the fear that nCPAP could disrupt sucking, swallowing, and breathing coordination and in turn induce deleterious cardiorespiratory events via laryngeal penetration and/or tracheal aspiration. Therefore, feeding strategy practices among neonatal care units are highly variable. Although some teams claim success with initiation of oral feeding in immature infants with nCPAP (3-5), many others strictly wait for nCPAP weaning before any attempt at oral feeding (6).

Given the risk of tracheal aspiration in fragile preterm infants under nCPAP, we believe studies in newborn animals are important to bring additional knowledge and ultimately refine translational studies in human preterms. With this goal in mind, we have previously shown in newborn lambs that bottle-feeding with a nCPAP up to $10 \mathrm{cmH}_{2} \mathrm{O}$ had no deleterious effects on both bottle-feeding efficiency and safety, and did not significantly alter swallowing and breathing coordination (7). Our results however were obtained in fullterm lambs accustomed to bottle-feeding, a condition fairly different from preterm infants learning to feed for the first time on nCPAP. Thereby, the main objective of the present study was to assess the impact of nCPAP on the introduction of bottle-feeding in preterm lambs, both in terms of bottlefeeding efficiency and safety as well as sucking-swallowingbreathing coordination. In addition, we further aimed to determine whether nCPAP had an impact on the evolution of these variables over $24 \mathrm{~h}$.

\section{METHODS}

The protocol of the study was approved by the Ethics Committee for Animal Care and Experimentation of the University of Sherbrooke (protocol \# 260-14).

\section{Animals}

The experiments were conducted on 17 preterm lambs (8 control and 9 nCPAP of $6 \mathrm{cmH}_{2} \mathrm{O}$ ) born 14 days prematurely as previously

${ }^{1}$ Neonatal Respiratory Research Unit, Departments of Pediatrics and Pharmacology - Physiology, Université de Sherbrooke, Sherbrooke, Quebec, Canada. Correspondence: Jean-Paul Praud (Jean-Paul.Praud@USherbrooke.ca)

Received 20 January 2017; accepted 26 April 2017; advance online publication 9 August 2017. doi:10.1038/pr.2017.162 
described (8). Briefly, premature labor was induced by mifepristone $(8 \mathrm{mg} / \mathrm{kg}$; Sigma-Aldrich, Oakville, Canada), after stimulation of lung surfactant maturation by intramuscular betamethasone $(12 \mathrm{mg} \times 2$; Schering-Plough Canada, Kirland, Canada). At birth, preterm lambs were randomly assigned to either the control or the nCPAP group. $\mathrm{Up}$ to the introduction of bottle-feeding, vital signs, including temperature, heart and respiratory rates, oxygen saturation, blood glucose level, and weight were regularly monitored.

\section{Chronic Instrumentation and Recording Equipment}

Chronic surgical instrumentation was performed under local anesthesia and included the insertion of (i) custom-built bipolar electrodes into both thyroarytenoid (EAta, a laryngeal constrictor) muscles for recording of swallowing activity (built from right-angled gold connectors, Sullins Connector Solutions, Digi-Key, Thief River Falls, MN); (ii) a catheter into the left carotid artery for sampling of arterial blood gases (RapidLab 348, Siemens, Saint-Laurent, Canada).

Instrumentation of the lambs was completed immediately before recordings and included (i) needle electrodes inserted subcutaneously for electrocardiogram (ECG) recordings (subdermal needle platinum iridium, Kego, London, Canada); (ii) elastic bands installed on the chest and abdomen to monitor lung volume variations semiquantitatively via respiratory inductance plethysmography (Ambulatory Monitoring, Ardsley, NY); (iii) a pulse oximetry probe (LNOP YI reflectance sensor, Masimo, Irvine, CA) placed at the base of the tail for continuous monitoring of oxygen hemoglobin saturation $\left(\mathrm{SpO}_{2}\right)$. In addition, a pressure catheter (Gaeltec model CTO-1, Medical Measurements, Hackensack, NJ) was introduced in the teat of the bottle to record sucking activity (positive expression amplitude). A plastic nasal mask custom-tailored for newborn lambs was installed on the lambs' muzzle just before bottle-feeding. The mask, designed in collaboration with the Department of Mechanical Engineering of the University of Sherbrooke, included two short nasal cannulas and was secured with a headgear. The interior of the mask was filled with dental paste to decrease the dead space $(<2 \mathrm{ml})$ and to prevent leaks. Lambs in the nCPAP group were connected to the Infant Flow nCPAP system (Cardinal Health, Dublin, OH), which delivered a variable-flow CPAP of $6 \mathrm{cmH}_{2} \mathrm{O}$. Control lambs were fed without the nasal mask. No oxygen was given to any of the lambs.

Physiological signals were transmitted wirelessly and continuously recorded (9). The entire recording period was filmed with a webcam, and an experimenter was present to note all the events occurring during the recordings (AcqKnowledge software, version 4.1, Biopac Systems Canada, Montreal, Canada).

\section{Design of the Study}

Following birth, all preterm lambs were cared for with their mother in our animal quarters and were fed via a nasogastric tube until the introduction of bottle-feeding ( 5 days of life). Thereafter, bottlefeeding with $40 \mathrm{ml}$ of ewe milk was introduced every $4 \mathrm{~h}$ for $24 \mathrm{~h}$ using a standardized procedure (7). Accordingly, the lambs were comfortably positioned prone in a sling (Lomir Biomedical, NotreDame-D'Ille-Perrot, Canada) with loose restraints. Throughout bottle-feeding, the head was maintained aligned with the body and the neck in extension, to mimic the natural position of a lamb feeding from an ewe. The bottle was offered to the lambs a maximum of three times, after which the feeding episode was considered finished. Reasons to stop feeding were mainly discomfort/agitation or refusal to feed. Recordings were continued for $15 \mathrm{~min}$ after bottlefeeding. Blood samples from the arterial catheter were taken immediately before feeding (obtained during nCPAP for the nCPAP group) and 1, 5, and 15 min thereafter.

\section{Data Analysis}

Data analysis was conducted in two steps. First, a detailed analysis was conducted as described hereafter during the first and last bottlefeeding attempts to answer the main objectives of the study. Thus, all signals were carefully observed and analyzed in relation to the time period (before, during, or after bottle-feeding) as well as with the nCPAP condition. The efficiency and safety of bottle-feeding as well as the coordination between sucking, swallowing, and breathing (rhythmic stability of feeding) were quantified as previously described (7) for the first and last bottle-feeding. The efficiency of bottle-feeding was quantified by feeding duration (s), the rate of milk transfer $(\mathrm{ml} / \mathrm{s})$, the total number of sucks (SU) and swallows (SW), and the mean expression amplitude (positive pressure applied to the teat in $\mathrm{mm} \mathrm{Hg}$ ) (10). The safety of bottle-feeding was quantified by the percentage of feeding duration spent in apnea (defined as at least two missed breaths with an amplitude $<30 \%$ compared to baseline breathing), the number of heart decelerations (defined by a \% decrease in $\mathrm{HR} \geq 33 \%$ for a maximum of $5 \mathrm{~s}$ ) and bradycardias (heart decelerations lasting $>5 \mathrm{~s}$ ), minimal heart rate (HR, per min), percentage decrease in HR (\%), total duration of cardiac inhibition (s), minimal $\mathrm{SpO}_{2}(\%)$, percentage decrease in $\mathrm{SpO}_{2}(\%)$, and number of coughs during bottle-feeding and within $30 \mathrm{~s}$ following bottle removal. The rhythmic stability of feeding (coefficient of variation $(\mathrm{COV})=\mathrm{SD}$ of the mean interval, divided by the mean interval (11)) was quantified by the time interval between SU-SU, SU-SW, SW-SW, and SW-breath (BR), as well as by the COV of SU-SU, SU-SW, SW-SW, and SW-BR. A lower COV value indicates a more stable rhythm. In addition, the percentage of SW occurring during an apnea was calculated. Finally, the respiratory rate (RR), $\mathrm{HR}$, mean $\mathrm{SpO}_{2}$, and blood gases $\left(\mathrm{PaCO}_{2}, \mathrm{PaO}_{2}\right.$, and $\left.\mathrm{pH}\right)$ were computed before and 1,5 , and $15 \mathrm{~min}$ after bottle-feeding.

The second step of the analysis was conducted on all bottle-feeding attempts and focused on the safety of bottle-feeding while on nCPAP. We investigated for the presence of cardiorespiratory events such as bradycardias, apneas, or desaturations, as well as for coughs, which might reflect laryngeal penetration or tracheal aspiration. If such events were observed, the number of lambs and the total number of events were compared between groups.

\section{Statistical Analysis}

Results were first averaged for each lamb and then averaged for each of the groups. Values are expressed as median (quartile 1 (Q1), quartile $3(\mathrm{Q} 3)$ ). The first and last bottle-feedings were considered individually. The Mann-Whitney $U$-test was used to test the effect of nCPAP. The Wilcoxon signed-rank test was used to test whether bottle-feeding performance improved between the first and last bottle-feeding attempt. All statistical analyses were performed with SPSS. A value of $P<0.05$ was considered statistically significant.

\section{RESULTS}

The study was completed in nine preterm lambs (five males) in the nCPAP group and eight preterm lambs (five males) in the control group. Six ewes gave birth to twins, two to triplets, two to a single lamb, and one ewe gave birth to quadruplets. Seven of the twenty-six lambs died from dystocia or neonatal respiratory distress (survival rate $71 \%$ ). The mean birth weight was $3.0(2.4,3.4) \mathrm{kg}$ in nCPAP lambs and $2.8(2.1,3.2)$ $\mathrm{kg}$ in control lambs.

\section{Detailed Analysis of the Effects of nCPAP on the First and Last Bottle-Feeding Attempts \\ First bottle-feeding attempt. Nasal CPAP increased bottle-} feeding efficiency for the first bottle-feeding attempt (Table 1). Accordingly, compared to the control group, the total number of SU and SW necessary to drink the entire bottle was lower in lambs with nCPAP, despite a lower stability of the SW-SW rhythm in nCPAP lambs. In addition, despite a significant increase in respiratory inhibition, $\mathrm{SpO}_{2}$ remained higher in nCPAP lambs, as shown in Figure 1 and Table 1 . No 


\section{Articles | Samson et al.}

Table 1. Effect of nCPAP and learning on the efficiency, safety and rhythmic stability of feeding for the first and last bottle-feeding in preterm lambs

\begin{tabular}{|c|c|c|c|c|}
\hline & \multicolumn{2}{|c|}{ First bottle-feeding } & \multicolumn{2}{|c|}{ Last bottle-feeding } \\
\hline & Control $(n=8)$ & $\operatorname{nCPAP}(n=9)$ & Control $(n=8)$ & $\mathrm{nCPAP}(\mathrm{n}=9)$ \\
\hline \multicolumn{5}{|l|}{ Efficiency } \\
\hline Rate of milk transfer $(\mathrm{ml} / \mathrm{s})$ & $1.0(0.8,1.4)$ & $1.4(0.7,2.4)$ & $1.2(1.0,1.7)$ & $2.9(2.4,3.2)^{*, \mp}$ \\
\hline Expression amplitude $(\mathrm{mm} \mathrm{Hg})$ & $26(22,29)$ & $17(14,31)$ & $34(24,38)$ & $25(23,30)$ \\
\hline \multicolumn{5}{|l|}{ Safety } \\
\hline Number of coughs & $0(0,0)$ & $0(0,0)$ & $0(0,0)$ & $0(0,2)$ \\
\hline Number of bradycardias & $0(0,1)$ & $0(0,1)$ & $0(0,0)$ & $0(0,0)$ \\
\hline Duration of cardiac inhibition (s) & $11(0,14)$ & $13(8,23)$ & $3(1,9)$ & $7(5,9)$ \\
\hline Minimal $\mathrm{SpO}_{2}(\%)$ & $80(79,83)$ & $93(90,93)^{*}$ & $84(81,91)$ & $95(92,96)^{*}$ \\
\hline$\%$ decrease in $\mathrm{SpO}_{2}$ & $14(13,16)$ & $3(3,7)^{*}$ & $11(4,16)$ & $2(1,3)$ \\
\hline Time in apnea/feeding duration (\%) & $27(17,54)$ & $100(27,100)$ & $45(17,90)$ & $100(100,100)^{*}$ \\
\hline \multicolumn{5}{|l|}{ Rhythmic stability of feeding } \\
\hline$\%$ SW during apnea & $45(17,91)$ & $91(41,100)$ & $50(21,92)$ & $100(100,100)^{*, \neq}$ \\
\hline COV SU-SU & $0.4(0.2,0.5)$ & $0.2(0.2,1.2)$ & $0.1(0.1,0.3)$ & $0.3(0.1,0.6)$ \\
\hline Interval SU-SU & $0.4(0.3,0.4)$ & $0.3(0.3,0.5)$ & $0.3(0.3,0.4)$ & $0.3(0.3,0.4)$ \\
\hline
\end{tabular}

$\mathrm{BR}$, breathing; COV, coefficient of variation of the time interval between $\mathrm{SU}$, SW and $\mathrm{BR}_{\text {; }} \mathrm{HR}$, heart rate; nCPAP, nasal continuous positive airway pressure of $6 \mathrm{cmH}_{2} \mathrm{O}$; SpO ${ }_{2}$, hemoglobin saturation; SU, sucking; SW, swallowing.

Results are presented as median (Q1, Q3).

${ }^{*} P<0.05$ vs. control lambs; ${ }^{\ddagger} P<0.05$ vs. nCPAP first bottle-feeding.

differences were noted between the two groups with regard to the number of cardiorespiratory events as well as for coughs. Finally, statistically significant differences were noted for some cardiorespiratory variables and arterial blood gases collected before $\left(\mathrm{PaO}_{2}\right)$ and after (RR) bottle-feeding (Table 2).

Last bottle-feeding attempt. Nasal CPAP again increased bottle-feeding efficiency during the last bottle-feeding, with both the feeding duration and total number of SW necessary to drink the entire bottle being lower compared to the control group (Table 1). Consequently, the rate of milk transfer was increased in nCPAP lambs. Again, $\mathrm{SpO}_{2}$ remained higher in nCPAP lambs (Figure 1 and Table 1), whereas no differences were noted regarding the number of cardiorespiratory events or coughs between groups. Moreover, a more stable SW-BR rhythm was observed in the nCPAP group, together with an increase in the percentage of SW occurring during an apnea (Table 1).

Evolution of bottle-feeding performance from the first to the last bottle-feeding attempt. In control lambs, no statistical differences were observed for any variable between the first and last bottle-feeding attempts. On the contrary, nCPAP lambs improved their bottle-feeding performance after $24 \mathrm{~h}$ by decreasing feeding duration as well as by increasing the rate of milk transfer (Table 1). Moreover, the percentage of SW occurring during an apnea in nCPAP lambs increased during the last bottle-feeding. Finally, aside from a lower $\mathrm{PaO}_{2}$ at 


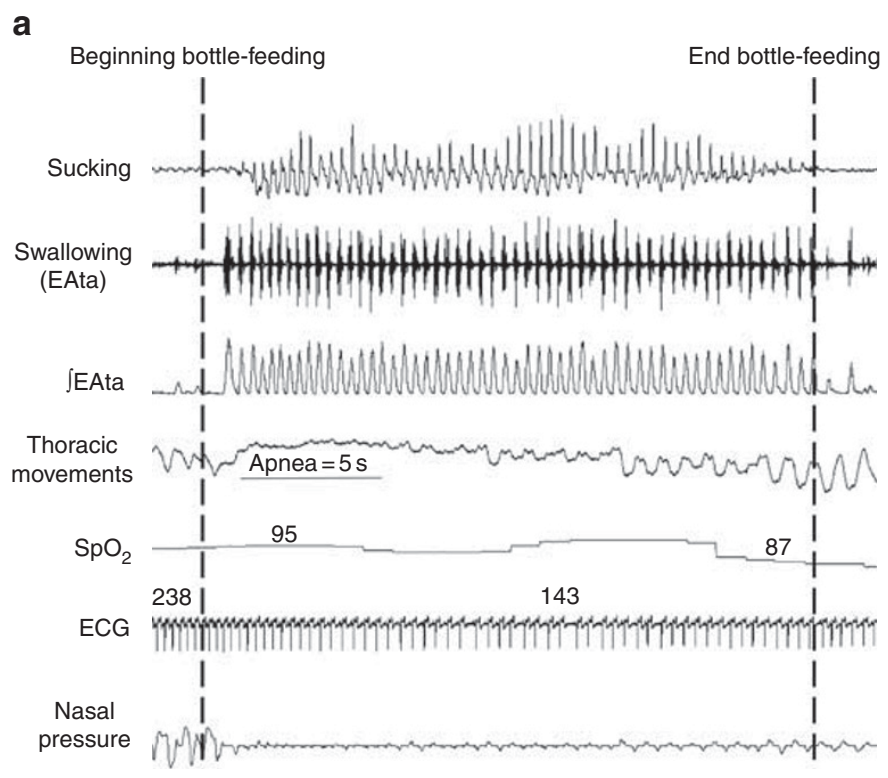

b

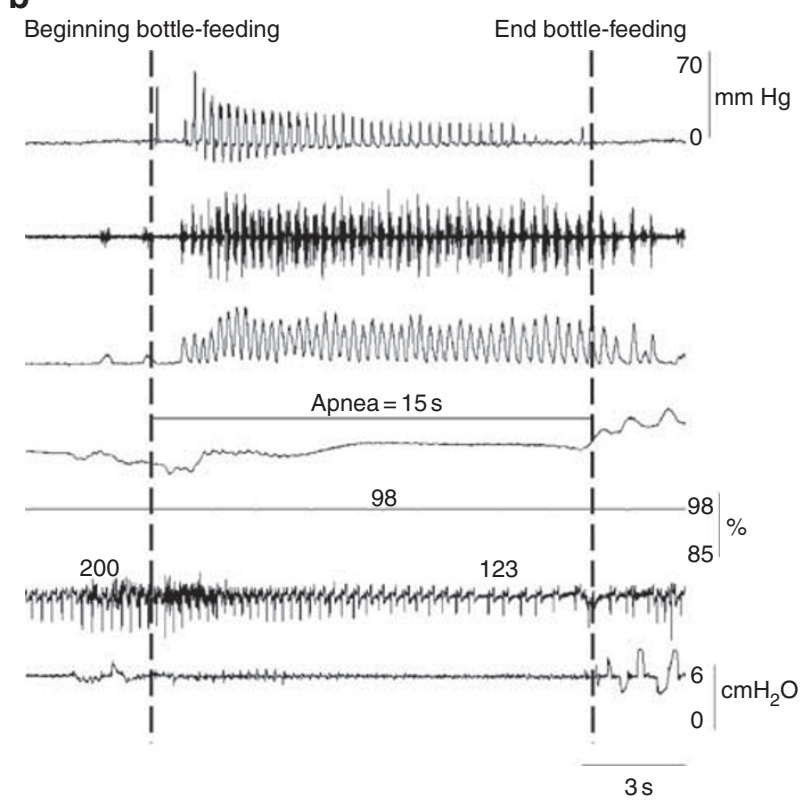

Figure 1. Sample tracing of bottle-feeding in one control (a) and one nCPAP (b) lamb. Despite an increase in respiratory inhibition, oxygenation remains higher in nCPAP lambs. Furthermore, a decrease in feeding duration and the total number of sucks and swallows is noticeable in the nCPAP compared to the control preterm lamb. Abbreviations used from top to bottom are as follows: sucking, positive expression pressure on the bottle teat; EAta, electrical activity of the thyroarytenoid muscle (glottal constrictor); $\int \mathrm{EAta}$, moving time averaged EAta; $\mathrm{SpO}_{2}$, hemoglobin saturation; $\mathrm{ECG}$, electrocardiogram.

5 min following the last bottle-feeding in nCPAP lambs, no statistical differences were noted for cardiorespiratory variables between the first and last bottle-feedings in either group (Table 2).

\section{Safety Analysis of all Bottle-Feeding Attempts}

Observation of each of the seven bottle-feeding attempts in all lambs showed that six nCPAP lambs presented with one or more cough episodes immediately after bottle removal during two to four bottle-feedings (i.e., during 17 attempts over a total of $63=27 \%$ ) compared to only one bottle-feeding attempt in one control lamb (over a total of 56 attempts = $2 \%)$. The sequence of events, which was observed in all lambs with coughs, consisted of apnea and bradycardia (when present) starting well before bottle removal, whereas cough, desaturation, and glottal closure occurred after bottle removal (Figures 2 and 3). In addition, a few premature ventricular contractions were observed in four nCPAP and three control lambs (Figure 3).

\section{DISCUSSION}

The present study conducted in a preterm lamb model akin to the late preterm infant $(\approx 34$ weeks) revealed that nCPAP of $6 \mathrm{cmH}_{2} \mathrm{O}$ increased bottle-feeding efficiency and oxygenation immediately upon the first bottle-feeding attempt. Moreover, only nCPAP lambs improved their bottle-feeding performance as well as the stability of their swallowing-breathing rhythm after $24 \mathrm{~h}$. Coughs were however more frequent within the $30 \mathrm{~s}$ following bottle removal in nCPAP lambs than in controls.

\section{State of the Art on the Introduction of Bottle-Feeding in Preterm Infants under nCPAP}

Introduction of oral feeding in preterm infants under nCPAP is currently a hot and controversial topic. On the one hand, many clinicians fear that nCPAP will lead to cardiorespiratory events via laryngeal penetration and/or tracheal aspiration. On the other, preterm infants fed orally on nCPAP (6$8 \mathrm{cmH}_{2} \mathrm{O}$ ) were found to achieve full oral feeding at an earlier age than a nCPAP gavage-fed group, and without any clinical signs suggesting aspiration pneumonia (3). Furthermore, the development of the aerodigestive reflexes in preterm infants did not differ when treated by nCPAP compared to the roomair breathing (12). The lack of evidence-based guidelines for feeding infants under nCPAP is due to the limited number of available studies, as well as the difficulty to assess the precise coordination between sucking, swallowing, and breathing in preterm infants under nCPAP (3-5). The above observation led us to use our established preterm lamb model allowing extensive assessment of sucking-swallowing-breathing coordination, in order to gain new physiological knowledge and thus refine the design of future clinical studies.

\section{Improvement of Bottle-Feeding Performance by nCPAP in Preterm Lambs}

Results of the present study reveal that bottle-feeding efficiency was improved in nCPAP lambs as early as the first 


\section{Articles | Samson et al.}

Table 2. Cardiorespiratory variables and arterial blood gases before and following bottle-feeding in preterm lambs

\begin{tabular}{|c|c|c|c|c|}
\hline & \multicolumn{2}{|c|}{ First bottle-feeding } & \multicolumn{2}{|c|}{ Last bottle-feeding } \\
\hline & Control $(n=8)$ & $\mathrm{nCPAP}(n=9)$ & Control $(n=8)$ & $\mathrm{nCPAP}(n=9)$ \\
\hline \multicolumn{5}{|l|}{ Before bottle-feeding } \\
\hline Respiratory rate (per min) & $30(29,44)$ & $30(27,36)$ & $32(27,37)$ & $27(27,30)$ \\
\hline $\mathrm{SpO}_{2}(\%)$ & $95(92,97)$ & $96(95,97)$ & $95(95,96)$ & $97(96,98)$ \\
\hline $\mathrm{pH}$ & $7.4(7.3,7.4)$ & $7.4(7.3,7.4)$ & $7.4(7.3,7.4)$ & $7.4(7.3,7.4)$ \\
\hline \multicolumn{5}{|l|}{ One minute after bottle-feeding } \\
\hline Heart rate (b.p.m.) & $171(164,192)$ & $168(164,172)$ & $166(161,186)$ & $184(172,212)$ \\
\hline $\mathrm{PaCO}_{2}(\mathrm{~mm} \mathrm{Hg})$ & $42(41,42)$ & $41(38,43)$ & $37(36,48)$ & $38(38,41)$ \\
\hline $\mathrm{pH}$ & $7.4(7.3,7.4)$ & $7.3(7.3,7.4)$ & $7.3(7.3,7.4)$ & $7.3(7.3,7.4)$ \\
\hline \multicolumn{5}{|l|}{ Five minutes after bottle-feeding } \\
\hline Heart rate (b.p.m.) & $184(160,232)$ & $188(180,224)$ & $170(151,213)$ & $196(188,252)$ \\
\hline Respiratory rate (per min) & $36(34,42)$ & $32(24,36)$ & $32(28,42)$ & $28(24,32)$ \\
\hline $\mathrm{SpO}_{2}(\%)$ & $95(89,97)$ & $96(95,97)$ & $96(94,97)$ & $96(94,97)$ \\
\hline $\mathrm{PaO}_{2}(\mathrm{~mm} \mathrm{Hg})$ & $101(97,104)$ & $103(94,117)$ & $95(91,102)$ & $95(90,104)^{\ddagger}$ \\
\hline $\mathrm{PaCO}_{2}(\mathrm{~mm} \mathrm{Hg})$ & $42(41,43)$ & $41(37,43)$ & $40(39,46)$ & $38(36,41)$ \\
\hline $\mathrm{PaO}_{2}(\mathrm{~mm} \mathrm{Hg})$ & $98(96,107)$ & $103(93,110)$ & $94(86,98)$ & $98(88,105)$ \\
\hline $\mathrm{PaCO}_{2}(\mathrm{~mm} \mathrm{Hg})$ & $42(39,43)$ & $40(33,43)$ & $39(34,46)$ & $39(36,42)$ \\
\hline $\mathrm{pH}$ & $7.4(7.3,7.4)$ & $7.3(7.3,7.4)$ & $7.3(7.3,7.4)$ & $7.4(7.3,7.4)$ \\
\hline
\end{tabular}

nCPAP, nasal continuous positive airway pressure of $6 \mathrm{cmH}_{2} \mathrm{O}_{1} \mathrm{PaCO}_{2}$, partial pressure of carbon dioxide in arterial blood; PaO , partial pressure of oxygen in arterial blood; $\mathrm{SpO}_{2}$, hemoglobin saturation.

Results are presented as median (Q1, Q3).

${ }^{*} P<0.05$ vs. control lambs; ${ }^{\ddagger} P<0.05$ vs. first bottle-feeding with nCPAP.

bottle-feeding attempt, when compared to controls. Several mechanisms can potentially explain this improved efficiency. It may first be related to the increased functional residual capacity, which promotes better oxygenation, and to the decreased work of breathing brought about by the variableflow nCPAP of $6 \mathrm{cmH}_{2} \mathrm{O}$ used in our study design (13). Secondly, with regard to sucking, while the expression amplitude (positive pressure applied to the teat) was not higher with nCPAP, we cannot rule out an increased sucking efficiency, as the suction amplitude (negative intraoral suction pressure) was not assessed. Thirdly, the larger bolus size at each swallow may be due to pharyngeal distension by nCPAP (14-16), allowing the accumulation of a greater volume of milk in the hypopharynx between two swallows. In this hypothesis, the higher percentage of time spent in apnea during bottle-feeding with nCPAP may provide more time to swallow, while contributing to prevent tracheal aspiration of this increased volume of milk in the pharynx.

The present study also shows that bottle-feeding performance was improved within the ensuing $24 \mathrm{~h}$ period in nCPAP lambs only, by decreasing feeding duration and increasing the rate of milk transfer. Again, several 
explanations can be proposed. With regard to sucking, while no increase in expression amplitude was observed, we lack information regarding suction amplitude, which may be increased. As for swallowing, in addition to the potential distension effect of the hypopharyngeal "reservoir" by nCPAP

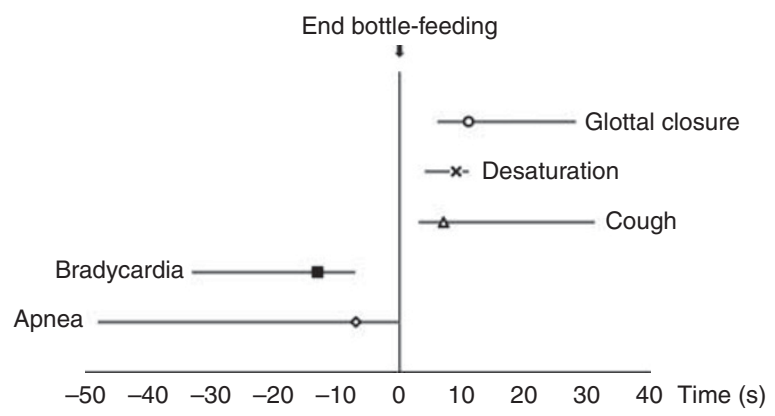

Figure 2. Sequence of events observed in the seven lambs presenting with a bout of coughs ( 6 nCPAP and 1 control lamb) during one or several bottle-feedings. Each symbol $(\diamond, \boldsymbol{\square}, \Delta, \times, \circ)$ represents the average, whereas the respective extremities of each segment bar represent the minimum and maximum duration time between the end of bottle-feeding (= zero time) and the onset of a given event (apnea, bradycardia, cough, desaturation, or laryngeal closure). The graph illustrates that the onset of cough, glottal closure, and desaturation is consistently after bottle removal, whereas apnea and bradycardia began during bottle-feeding.
(14-16), the increased percentage of SW occurring during an apnea as well as the more rhythmic coordination between swallowing and breathing during the last bottle-feed may contribute in explaining the increased performance within the 24-h time frame.

\section{Coordination Between Sucking, Swallowing, and Breathing During Bottle-feeding in Preterm Lambs}

In agreement with the results obtained in human infants (17-19), we observed that half of the nutritive swallows occurred during an apnea in control preterm lambs, which is substantially greater than the $10 \%$ previously observed in full-term lambs (7). Moreover, while nCPAP further increased the percentage of swallows occurring during an apnea to $90-100 \%$ in preterm lambs, this was not the case in full-term lambs (7). Although we have no true explanation to account for this difference related to gestational age, it may be that both swallowing and nCPAP have a stronger inhibitory effect on breathing in preterms.

\section{Safety of Bottle-Feeding under nCPAP}

The safety of bottle-feeding preterm infants while on nCPAP continues to raise many questions, which are fueled by the paucity of available data. A recent study showed that preterm infants under nCPAP have the same ability to initiate

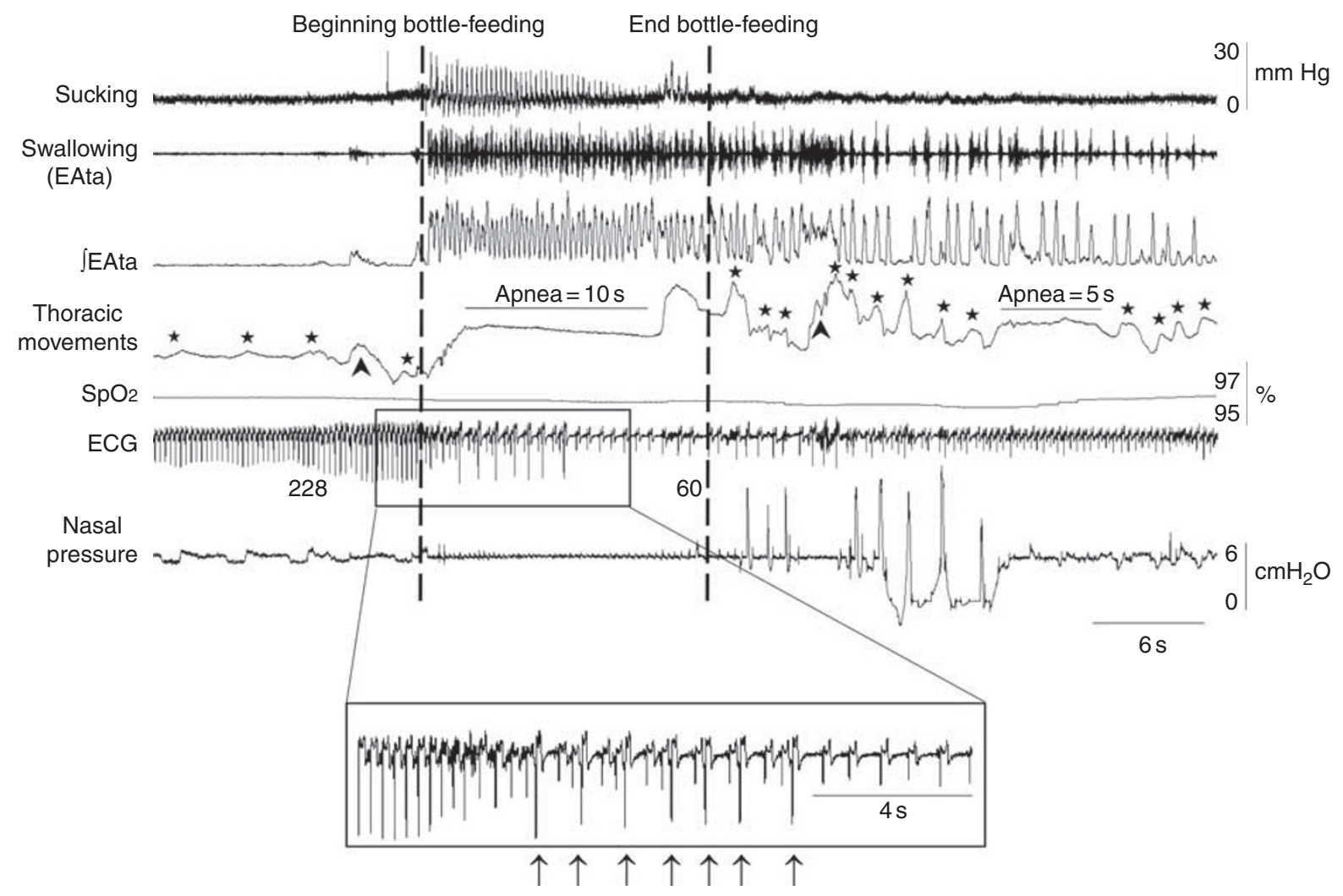

Figure 3. Sample tracing of bottle-feeding followed by a bout of coughs in one nCPAP lamb. Central apnea and bradycardia are present throughout bottle-feeding (limited by the two dotted lines) after which a bout of seven coughs is observed, beginning $2 \mathrm{~s}$ after bottle removal. See Figure 1 for abbreviations. $\star$, inspiration; arrowhead, obstructed breaths against a closed larynx. In addition, in this particular lamb, an epoch of seven premature ventricular contractions $(\uparrow)$ occurring in a mixed trigeminy and bigeminy pattern is magnified at the bottom of the figure. 


\section{Articles | Samson et al.}

pharyngeal reflexive swallowing as their room-air-breathing counterparts and concluded that preterms can protect and clear a pharyngeal bolus with appropriate proximal peristaltic mechanism (12). Conversely, results from a recent videoscopic study in preterm infants suggest that nCPAP alters pharyngeal swallows and increases the risk of tracheal aspiration during oral feeding (20). Overall, our present results showing better oxygenation in nCPAP lambs during bottle-feeding, together with the absence of deleterious cardiac events, is reassuring. The presence of coughs in nCPAP lambs immediately following bottle removal continues however to question the association between nCPAP and the risk of laryngeal/tracheal aspiration. From a mechanistic standpoint, our unique observations that coughs were consistently observed after bottle removal suggest that, if present, laryngeal and/or tracheal aspiration would be due to the residual milk in the pharynx when inspiration resumes following the apneic state during bottle-feeding. We believe that several factors related to preterm lambs and/or to our experimental design may have increased the volume of residual milk in the pharynx at the time of breathing resumption. Such possible factors include the following: (i) the remarkable rapidity (compared to preterm infants) with which preterm lambs feed from a bottle; (ii) our experimental design that allowed the lambs to drink the entire bottle as quickly as desired without imposed pauses at predetermined volumes, and/or (iii) the increased possibility for milk to be stocked in the hypopharyngeal "reservoir" dilated by nCPAP (14-16). The consequent increased volume of milk remaining to be swallowed when respiration resumed after bottle removal may have transiently overwhelmed their swallowing-breathing coordination.

\section{Limitations of the Study}

As already alluded to earlier, the goal of the present study was to assess the effects of nCPAP on the physiology of nutritive swallowing and sucking-swallowing-breathing coordination in an ovine model of preterm newborn. Although the ultimate goal is to better inform future translational studies in preterm humans, several limitations to our current model should be recognized with regard to its clinical relevance in preterm infants requiring nCPAP for breathing difficulties.

First, our preterm lamb model is more akin to the late preterm $(\approx 34$ weeks $)$ than to the extreme premature infant. However, introduction of oral feeding in preterm infants is often initiated at about this time of post-conceptional age. Also, our results were obtained in healthy preterm lambs, and previous studies have shown abnormal swallowing-breathing coordination in preterm infants with bronchopulmonary dysplasia (21). In addition, lambs in the present study were carefully maintained in the prone position with the neck extended, which is quite different from the position used to bottle-feed a human newborn.

Secondly, our results obtained with nCPAP delivered by the Infant Flow System may not be valid for nCPAP delivered by another system such as bubble-CPAP or CPAP generated by NICU ventilators. In particular, negative effects on bottlefeeding might be obtained when using the latter, which is claimed to be less steady and less accurate than nCPAP delivered by the Infant Flow System (22). In addition, our results obtained with nCPAP do not provide any information on the potential effect of high flow nasal cannula, another type of neonatal respiratory support much in use in neonates. Moreover, the fact that a non-leaky nasal mask was used in the present study must be underlined. Indeed, mask leaks are frequent in human newborns, which may have different effects on bottle-feeding.

Thirdly, the presence of laryngeal penetrations and/or tracheal aspirations was assessed only by the cough reflex, which implies that silent aspirations may have been missed. Finally, the presence of coughs at the end of bottle-feeding in the present study may be clinically irrelevant for breastfed infants, due to the much less rapid milk flow compared to bottle-feeding in lambs. Thus, the present results obtained herein must be complemented by further physiological studies in preterm lambs with moderate respiratory difficulties requiring $\mathrm{nCPAP}$, while looking more carefully for silent tracheal aspirations using videoradiography as well as altering the rapidity of milk flow.

\section{CONCLUSION}

In conclusion, nCPAP positively influences bottle-feeding in preterm lambs by increasing arterial oxygenation as well as the stability of swallowing-breathing rhythm and feeding efficiency. We hypothesize that the increase in coughs following bottle removal under nCPAP is mainly related to the very high milk flow; if correct, this could be easily prevented by pauses during bottle-feeding and would moreover be much less of a concern in breastfed infants.

\section{STATEMENT OF FINANCIAL SUPPORT}

This study was supported by an operating grant from the Canadian Institutes of Health Research. J-PP is the holder of the Canada Research Chair in Neonatal Respiratory Physiology and a member of the Research Center, Centre Hospitalier Universitaire de Sherbrooke.

Disclosure: The authors declare no conflict of interest

\section{REFERENCES}

1. Pickler RH, Chiaranai C, Reyna BA. Relationship of the first suck burst to feeding outcomes in preterm infants. J Perinat Neonatal Nurs 2006;20: $157-62$.

2. Simpson C, Schanler RJ, Lau C. Early introduction of oral feeding in preterm infants. Pediatrics 2002;110:517-22.

3. Hanin M, Nuthakki S, Malkar MB, Jadcherla SR. Safety and efficacy of oral feeding in infants with BPD on nasal CPAP. Dysphagia 2015;30: 121-7.

4. Maastrup R, Bojesen SN, Kronborg H, Hallström I. Breastfeeding support in neonatal intensive care: a national survey. J Hum Lact 2012;28: 370-9.

5. Bonner KM, Mainous RO. The nursing care of infant receiving bubble CPAP therapy. Adv Neonat Care 2008;8:78-95.

6. Nyqvist KH. Early attainment of breastfeeding competence in very preterm infants. Acta Paediatr 2008;97:776-81. 
7. Bernier A, Catelin C, Hadj Ahmed MA, Samson N, Bonneau P, Praud JP. Effects of nasal continuous positive-airway pressure on nutritive swallowing in lambs. J Appl Physiol 2012;112:1984-91.

8. Boudaa N, Samson N, Carrière V, et al. Effects of caffeine and/or nasal CPAP treatment on laryngeal chemoreflexes in preterm lambs. J Appl Physiol 2012;114:637-46.

9. Samson N, Dumont S, Specq ML, Praud JP. Radio telemetry devices to monitor breathing in non-sedated animals. Respir Physiol Neurobiol 2011;179:111-8.

10. Lau C, Sheena HR, Shulman RJ, Schanler RJ. Oral feeding in low birth weight infants. J Pediatr 1997;130:561-9.

11. Gewolb IH, Fishman D, Qureshi MA, et al. Coordination of suck-swallow-respiration in infants born to mothers with drug-abuse problems. Dev Med Child Neurol 2004;46:700-5.

12. Jadcherla SR, Hasenstab KA, Sitaram S, Clouse BJ, Slaughter JL, Shaker R. Effect of nasal noninvasive respiratory support methods on pharyngeal provocation-induced aerodigestive reflexes in infants. Am J Physiol Gastrointest Liver Physiol 2016;310:G1006-14.

13. Courtney SE, Aghai ZH, Saslow JG, Pyon KH, Habib RH. Changes in lung volume and work of breathing: a comparison of two variable-flow nasal continuous positive airway pressure devices in very low birth weight infants. Pediatr Pulmonol 2003;36:248-52.

14. Kuźniar TJ, Morgenthaler TI, Prakash UB, Pallanch JF, Silber MH, Tippmann-Peikert M. Effects of continuous positive airway pressure on stridor in multiple system atrophy-sleep laryngoscopy. J Clin Sleep Med 2009;5:65-7.

15. Sinha B, Castro-Aragon I, Wachman EM, Fujii AM, Levesque BM. Hypo-pharyngeal distension in an extremely low birth weight preterm infant. Arch Dis Child Fetal Neonatal 2015;100:F500.

16. Walor D, Berdon W, Anderson N, Holt PD, Fox M. Gaseous distention of the hypopharynx and cervical esophagus with nasal CPAP: a mimicker of pharyngeal perforation and esophageal atresia. Pediatr Radiol 2005;35: 1196-8.

17. Gewolb IH, Vice FL. Maturational changes in the rhythms, patterning, and coordination of respiration and swallow during feeding in preterm and term infants. Dev Med Child Neurol 2006;48:589-94.

18. Lau C, Smith EO, Schanler RJ. Coordination of suck-swallow and swallow respiration in preterm infants. Acta Paediatr 2003;92:721-7.

19. Mizuno K, Ueda A. The maturation and coordination of sucking, swallowing, and respiration in preterm infants. J Pediatr 2003;142:36-40.

20. Ferrara L, Bidiwala A, Sher I, et al. Effect of nasal continuous positive airway pressure on the pharyngeal swallow in neonates. J Perinatol 2017;37:398-403.

21. Gewolb IH, Vice FL. Abnormalities in the coordination of respiration and swallow in preterm infants with bronchopulmonary dysplasia. Dev Med Child Neurol 2006;48:595-9.

22. Alexiou S, Panitch HB. Physiology of non-invasive respiratory support. Semin Fetal Neonatal Med 2016;21:174-80. 